\title{
PRIMARY AMENORRHEA IN KABUKI SYNDROME: A CASE REPORT
}

\section{Nandha Kumar Subbiah ${ }^{1}$, Sarah Ramamurthy ${ }^{* 2}$, Aravindhan Karuppusamy ${ }^{3}$}

${ }^{1}$ Assistant Professor of Anatomical Sciences, Medical University of the Americas, St. Kitts and Nevis.

${ }^{* 2}$ Assistant Professor, Department of Anatomy, Pondicherry Institute of Medical Sciences, Kalapet, Pondicherry, India.

${ }^{3}$ Additional Professor and Head, Department of Anatomy, JIPMER, Pondicherry, India.

\section{ABSTRACT}

Kabuki syndrome also called as Niikawa Kuroki syndrome is a paediatric congenital disorder characterised by distinctive facial features, skeletal anomalies, short stature, dermatoglyphic abnormalities and mental retardation. This syndrome usually manifests with precocious puberty. We are presenting a case of Kabuki syndrome from the South-Indian population with primary amenorrhea for the first time. Further, the clinical features had considerable overlap with Turner syndrome, and chromosomal analysis revealed the presence of ring (X) chromosome with 45,X karyotype.

KEY WORDS: Kabuki syndrome, Comet assay, Turner syndrome, Ring chromosome.

Address for Correspondence: Dr Sarah Ramamurthy, Assistant Professor, Department of Anatomy, Pondicherry Institute of Medical Sciences, Kalapet, Pondicherry, India. Phone:9962267590

E-Mail: drsarahsenthilkumar@gmail.com

Access this Article online

Quick Response code

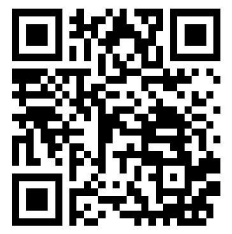

DOI: $10.16965 /$ ijar.2018.192

Journal Information

International Journal of Anatomy and Research

ICV for 2016 ISSN (E) 2321-4287 | ISSN (P) 2321-8967

90.30 https://www.ijmhr.org/ijar.htm

DOI-Prefix: https://dx.doi.org/10.16965/ijar

Article Information

Received: 20 Mar 2018

Peer Review: 20 Mar 2018

Revised: None
Accepted: 08 May 2018

Published (O): 05 Jun2018

Published (P): 05 Jun 2018

\section{INTRODUCTION}

Kabuki syndrome also called as Niikawa - Kuroki syndrome is a paediatric congenital disorder characterized by distinctive facial features, skeletal anomalies, short stature, dermatoglyphic abnormalities and mental retardation. The syndrome was initially known to occur in Japan, but now it is known to occur in many other ethnic groups. Incidence is 1 in 32000 live births $[1,2]$. We are presenting here a typical Kabuki syndrome presenting with primary amenorrhea for the first time reported from Indian population.

\section{CASE PRESENTATION}

An 18-year-old female was referred to cytogenetics division of the department of Anatomy,
JIPMER from Obstetrics and Gynaecology department of JIPMER to evaluate the cause of primary amenorrhea. Written informed consent was obtained from the participant before clinical examination.

On eliciting family history, the subject's mother reported that she was a second child born of a second-degree consanguineous marriage (Figure.1). At birth, her weight was $2.25 \mathrm{~kg}$, she was small for gestational age, birth length was $45 \mathrm{~cm}$, and head circumference was small 32.4 $\mathrm{cm}\left(50^{\text {th }}\right.$ percentile). The mother reported delayed developmental milestones (she started speaking and walking at the age of 3) and history of recurrent respiratory infections since childhood.

Clinical Examination: On Clinical examination, 
she was short-statured for her age (height -135 $\mathrm{cm}$ ) and had cubitus valgus (Figure $2 \mathrm{a}$ ) with poorly developed secondary sexual characters - breast tanner stage 2 and absent axillary and pubic hair. She had distinct facial features such as arched eyebrows, long palpebral fissures, long eyelashes, hypertelorism, depressed nasal tip, low set large prominent ears with poor facial expression (Figure $2 b$ and $2 c$ ). She also had high arched palate and malocclusion (Figure 2d) moreover, short fifth metacarpal (Figure 2e). On IQ assessment, she had mild mental retardation.

Investigations: CVS examination was normal. Echocardiogram done revealed no cardiovascular abnormality.

$X$-ray radiography: $X$-ray of the spine, Lateral view and $\mathrm{X}$-ray shoulder showed no skeletal abnormalities and $\mathrm{X}$-ray pelvis, AP view was normal.

Chromosomal analysis: Conventional karyotyping with GTG banding was done in peripheral blood lymphocytes. 100 metaphase spreads were captured which revealed the presence of $45, X$ karyotype in most of the spreads and ring chromosome in few of the spreads $45, X+r(X)$ (Figure 3).

Comet assay: Comet assay revealed significantly increased values of comet parameters such as head diameter, tail length and percentage of DNA in the tail as compared to normal individuals. (Figure 4 and Table 1 ).

Table 1: Comparison of comet parameters between Kabuki syndrome and normal female.

\begin{tabular}{|c|c|c|}
\hline Parameters & $\begin{array}{c}\text { Kabuki syndrome } \\
(\mathbf{4 5 , X})\end{array}$ & $\begin{array}{c}\text { Normal } \\
(\mathbf{4 6 , X X})\end{array}$ \\
\hline Comet Length $(\mu \mathrm{m})$ & 65.05 & 52.31 \\
\hline Head Diameter $(\mu \mathrm{m})$ & 35.28 & 24.86 \\
\hline \%DNA in Head & 73.21 & 71.45 \\
\hline Tail Length $(\mu \mathrm{m})$ & 29.77 & 25.46 \\
\hline \%DNA in Tail & 26.79 & 3.74 \\
\hline
\end{tabular}

Table 2: Hormonal profile.

\begin{tabular}{|c|c|c|}
\hline Hormones & Values (normal range) & Observation \\
\hline FSH & $40.1 \mathrm{mIU} / \mathrm{mL}(1.5-33.4)$ & Increased \\
\hline LH & $2.9 \mathrm{mIU} / \mathrm{mL}(0.5-76.3)$ & Normal \\
\hline Estradiol & $38.3 \mathrm{pg} / \mathrm{mL}(20-570)$ & Normal \\
\hline Progesterone & $0.23 \mathrm{ng} / \mathrm{mL}(0.15-28.03)$ & Normal \\
\hline Prolactin & $7.6 \mathrm{ng} / \mathrm{mL}(2.8-29.2)$ & Normal \\
\hline
\end{tabular}

Ultrasound examination revealed a hypoplastic uterus $-1.8 \times 6 \mathrm{~mm}$ size and absent ovaries.

Hormonal profile revealed an increased level of FSH (Table 2).

Fig. 1: Pedigree chart.

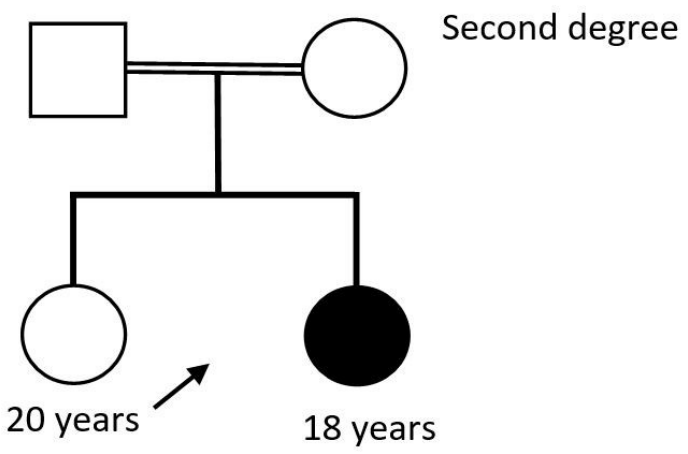

Fig. 2: Clinical features of Kabuki syndrome.

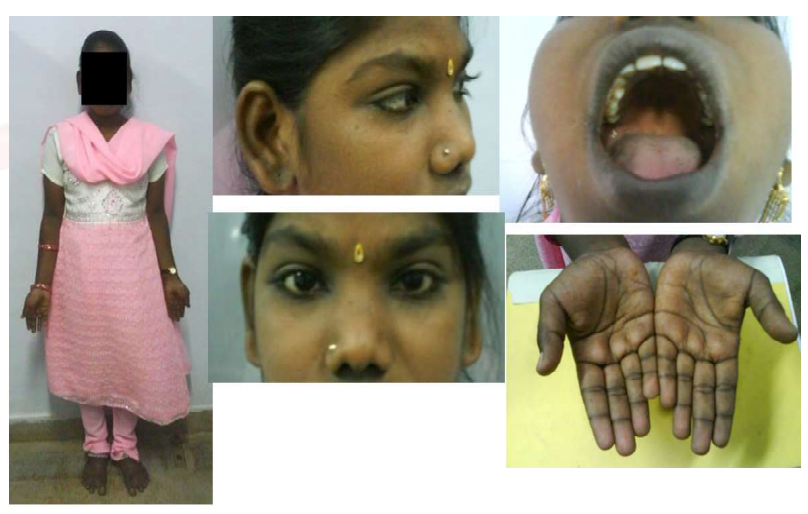

Fig. 3: Kabuki karyotype with ring chromosome.

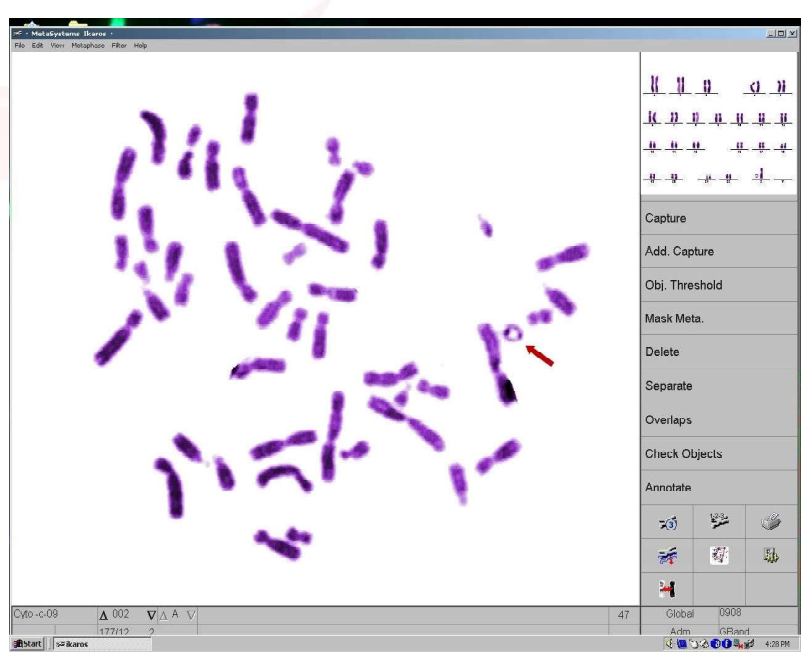

Fig. 4: Comet assay $-4 a$. Kabuki syndrome 4b. Normal karyotype.

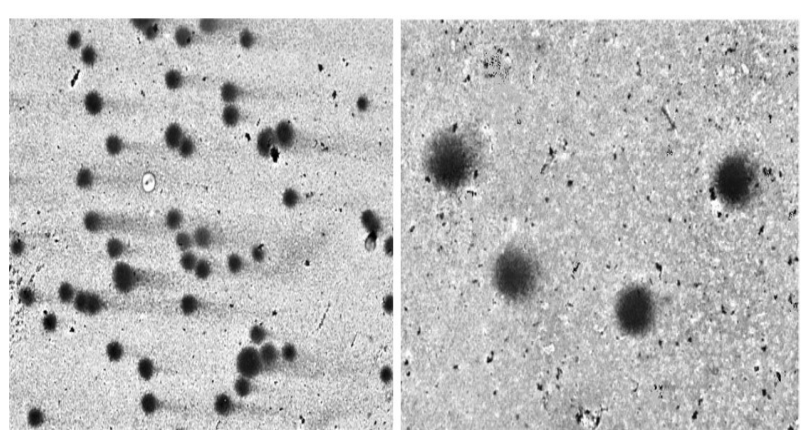




\section{DISCUSSION}

Kabuki syndrome was considered to be rare disorder of Autosomal dominant inheritance [1] Despite racial differences, it has been suggested that minimal criteria for the diagnosis of Kabuki syndrome include long palpebral fissure with eversion of lower eyelids, dysmorphic facies, broadly arched eyebrows with sparse lateral hair, depressed nasal tip, prominent ears and developmental delay with mental retardation [3]. Our case manifested with all these features. Based on the clinical picture and facial features a diagnosis of Kabuki syndrome was made.

The hallmark features of Kabuki syndrome as mentioned in the previous literature such as delayed milestones [4], speech delay with articulation abnormalities [5] and mental retardation [3] were marked in this case. Two third of subjects with this syndrome present with the high arched palate and dental abnormalities [6] and it was noted in this case. Our case did not show any specific pattern of inheritance as there was no family history of similar feature $[1,7]$. History of recurrent infection in childhood would have been due to immunodeficiency with hypogammaglobulinemia [1,8].

Literature review reported precocious puberty in many cases of Kabuki syndrome [9]. In our case, the girl presented with Primary amenorrhea. This may be attributed to the chromosomal complement $45, X+r(X)$ pertaining to Turner syndrome found in most of the cell lines. Presence of ring chromosome in Kabuki syndrome has been reported earlier $[10,11]$. To the best of our knowledge, this is the first case of Kabuki syndrome with primary amenorrhea to be reported in India.

Increased follicular stimulating hormone observed in our case could be attributed to the absent ovaries. This is similar to Turner syndrome. Further, there is considerable overlapping of clinical features of Kabuki syndrome with Turner syndrome along with 45, $\mathrm{X}$ karyotype. Kabuki syndrome can occur in both the genders whereas, Turner syndrome occurs only in females [4]. Currently, there are no specific investigations available for Kabuki syndrome. Diagnosis is made mainly based on cardinal clinical features and clinicians should have a sound knowledge about the syndrome to rule out the conditions such as Di George syndrome and van der Woude syndrome which has overlapping features with Kabuki syndrome. Literature study shows KDM6A and KMT2D and XIST gene mutation observed in many patients [12]. In our study, we have not performed PCR analysis to identify the mutation to rule out the molecular level of abnormality.

Literature search revealed that Comet analysis was not performed for Kabuki syndrome till now. We performed comet analysis which showed increased comet parameters when compared to normal individual accounting for the chromosomal damage in utero which would have resulted in mental retardation and other clinical features associated with the syndrome [13].

Till date, there is no definite treatment option available. Growth hormone supplementation can be given to increase the height of the individual and hence it was given to the subject $[4,7]$ and we have observed a 3-cm increase in height after one year. Estrogen supplementation was given to improve secondary sexual characters \& to prevent cardiovascular complications \& osteoporosis.

\section{Conflicts of Interests: None}

\section{REFERENCES}

[1]. Niikawa N, Kuroki Y, Kajii T, Matsuura N, Ishikiriyama $\mathrm{S}$, Tonoki $\mathrm{H}$, et al. Kabuki make-up (Niikawa-Kuroki) syndrome: A study of 62 patients. American Journal of Medical Genetics. 1988;31(3):565-89.

[2]. Kuroki Y, Suzuki Y, Chyo H, Hata A, Matsui I. A new malformation syndrome of long palpebralfissures, large ears, depressed nasal tip, and skeletal anomalies associated with postnatal dwarfism and mental retardation. The Journal of pediatrics.99(4):5703.

[3]. Kawame H, Hannibal MC, Hudgins L, Pagon RA. Phenotypic spectrum and management issues in Kabuki syndrome. The Journal of pediatrics. 1999;134(4):480-5.

[4]. Adam MP, Hudgins L. Kabuki syndrome: a review. Clinical Genetics. 2005;67(3):209-19.

[5]. Upton S, Stadter CS, Landis P, Wulfsberg EA. Speech characteristics in the Kabuki syndrome. American Journal of Medical Genetics Part A. 2003;116A(4):338-41.

[6]. Matsune K, Shimizu T, Tohma T, Asada Y, Ohashi H, Maeda T. Craniofacial and dental characteristics of Kabuki syndrome. American Journal of Medical Genetics. 2001;98(2):185-90. 
[7]. Bögershausen N, Wollnik B. Unmasking Kabuki syndrome. Clinical Genetics. 2013;83(3):201-11.

[8]. Schrander-Stumpel C, Meinecke P, Wilson G, Gillessen-Kaesbach G, Tinschert S, Konig R, et al. The Kabuki (Niikawa-Kuroki) syndrome: further delineation of the phenotype in 29 non-Japanese patients. Eur J Pediatr. 1994;153(6):438-45.

[9]. Kuroki Y, Katsumata N, Eguchi T, Fukushima Y, Suwa $\mathrm{S}$, Kajii T. Precocious puberty in Kabuki makeup syndrome. The Journal of pediatrics. 1987;110(5):7502.

[10]. McGinniss MJ, Brown DH, Burke LW, Mascarello JT, Jones MC. Ring chromosome $X$ in a child with manifestations of Kabuki syndrome. American Journal of Medical Genetics. 1997;70(1):37-42.

[11]. Stankiewicz P, Thiele H, Giannakudis I, Schlicker M, Baldermann C, Kruger A, et al. Kabuki syndromelike features associated with a small ring chromosome $X$ and XIST gene expression. Am J Med Genet. 2001;102(3):286-92.
[12]. Cheon CK, Sohn YB, Ko JM, Lee YJ, Song JS, Moon JW, et al. Identification of KMT2D and KDM6A mutations by exome sequencing in Korean patients with Kabuki syndrome. Journal of human genetics. 2014;59(6):321-5.

[13].Ramamurthy S, Chand P, Chaturvedula L, Ramachandra Rao K. Deoxiribonucleic acid damage study in primary amenorrhea by comet assay and karyotyping. Indian Journal of Human Genetics. 2013;19(4):397-403.

How to cite this article:

Nandha Kumar Subbiah, Sarah Ramamurthy, Aravindhan Karuppusamy. PRIMARY AMENORRHEA IN KABUKI SYNDROME: A CASE REPORT. Int J Anat Res 2018;6(2.3):5306-5309. DOI: 10.16965/ijar.2018.192 